\title{
Thermal infrared emission spectroscopy of titanium-enriched pyroxenes
}

\author{
V. E. Hamilton \\ Hawai'i Institute of Geophysics and Planetology, University of Hawai'i, Honolulu, Hawaii, USA
}

Received 23 January 2003; revised 11 April 2003; accepted 6 May 2003; published 26 August 2003.

[1] Pyroxenes are useful indicators of igneous processes and may be identified in geologic materials in the laboratory or remotely through the use of spectroscopic analysis. Studies of the thermal infrared (vibrational) spectra of many compositions in the pyroxene solid solution series (quadrilateral orthopyroxene and clinopyroxene, and some nonquadrilateral compositions) have shown that spectral absorption features shift in wavelength position, vary in number, and change shape as a function of pyroxene silicate structure and cation substitution. These spectral variations can be used to identify the approximate composition(s) of pyroxenes in the thermal infrared emission spectra of rocks. Here I demonstrate that the spectra of Ti-rich calcic clinopyroxenes also have thermal infrared spectral characteristics that distinguish them from typical quadrilateral compositions via a comparison to the spectrum of Angra dos Reis, a meteorite dominated by Ti-enriched clinopyroxene. The distinctive spectral character of Ti-rich pyroxenes may permit their identification not only in laboratory mineral and rock samples but also in thermal infrared remote sensing data, providing additional chemical information about igneous lithologies. INDEX TERMS: 3694 Mineralogy and Petrology: Instruments and techniques; 3672 Mineralogy and Petrology: Planetary mineralogy and petrology (5410); 3640 Mineralogy and Petrology: Igneous petrology; 3655 Mineralogy and Petrology: Major element composition; 5464 Planetology: Solid Surface Planets: Remote sensing; KEYWORDS: Pyroxene, infrared spectroscopy, thermal emission, Angra dos Reis, remote sensing

Citation: Hamilton, V. E., Thermal infrared emission spectroscopy of titanium-enriched pyroxenes, J. Geophys. Res., 108(E8), 5095, doi:10.1029/2003JE002052, 2003.

\section{Introduction and Background}

[2] Infrared spectroscopy is one approach to determining the composition and structure of unknown mineral samples. Specifically, the interaction of photons with the stretching and bending vibrations of $\mathrm{SiO}_{4}$ anion groups dominates spectra of silicate minerals in the thermal infrared region (2000-200 $\left.\mathrm{cm}^{-1} ; \sim 5-50 \mu \mathrm{m}\right)$, forming large absorption features called reststrahlen bands. Additional features are related to chain bending, lattice, and metal-oxygen vibrations. The shape and number of reststrahlen bands are indicative of the variations in the vibrational modes that result from cation coordination and substitution of cations in the mineral structure.

[3] Pyroxenes are the second most prevalent mineral following feldspars, present generally as stable phases in most types of igneous rocks, and in many types of metamorphic rocks. They are silicate minerals with a general formula of $\mathrm{XYZ}_{2} \mathrm{O}_{6}$, where $\mathrm{X}$ represents $\mathrm{Na}^{+}, \mathrm{Ca}^{2+}, \mathrm{Mn}^{2+}, \mathrm{Fe}^{2+}$, $\mathrm{Mg}^{2+}$, and $\mathrm{Li}^{+}$in the $\mathrm{M} 2$ site; $\mathrm{Y}$ represents $\mathrm{Mn}^{2+}, \mathrm{Fe}^{2+}, \mathrm{Mg}^{2+}$, $\mathrm{Fe}^{3+}, \mathrm{Al}^{3+}, \mathrm{Cr}^{3+}$, and $\mathrm{Ti}^{4+}$ in the $\mathrm{M} 1$ site; and $\mathrm{Z}$ represents $\mathrm{Si}^{4+}$ and commonly $\mathrm{Al}^{3+}$ [Cameron and Papike, 1982]. Distinctions between pyroxene chemistries provide a means of discerning more than just the presence of pyroxene - they

Copyright 2003 by the American Geophysical Union. 0148-0227/03/2003JE002052\$09.00 can provide important information about the magma from which the rock was derived (e.g., alkaline vs. tholeiitic).

[4] Pyroxenes have been the subject of numerous thermal infrared transmission [Lazarev and Tenisheva, 1961a, 1961b; Lyon, 1962; Ryall and Threadgold, 1966; Estep et al., 1971, 1972; Omori, 1971; Rutstein and White, 1971; Kuznetsova et al., 1980], reflection [Lyon, 1962], and emission [Hamilton, 1998, 2000] spectroscopic studies. These studies have documented changes in thermal infrared spectral absorption features (shifts in wavelength position, variations in number, and changes in shape) that occur as a function of pyroxene silicate structure and cation substitution. Hamilton et al. [1997] and Hamilton and Christensen [2000] demonstrated that spectral variations among many pyroxenes are sufficiently distinct to be used to quantify the approximate modal abundance (to within 5-10 vol.\%) and composition(s) (clino- vs. orthopyroxene, quadrilateral vs. nonquadrilateral, and $\mathrm{Mg} /(\mathrm{Mg}+\mathrm{Fe})$ to within $10-15 \mathrm{Mg})$ of pyroxenes in the thermal infrared emission spectra of natural rock samples. Because of the potential utility of identifying specific pyroxene compositions in laboratory or remote sensing spectroscopic data, it is important to continue studying how chemical variations (i.e., solid solution) influence the infrared spectra of pyroxenes.

[5] An unresolved question about pyroxene spectral character as a function of composition was identified by 


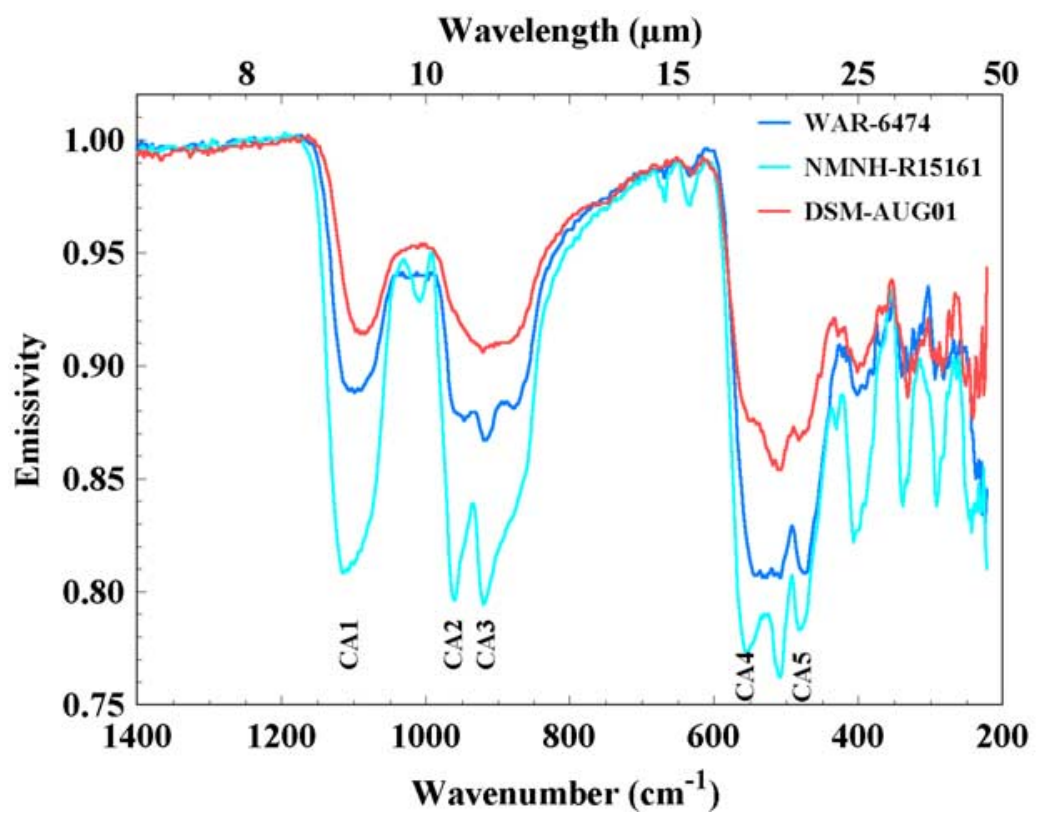

Figure 1. Thermal infrared emission spectra of calcic clinopyroxenes. WAR-6474 and NMNH-R15161 provide examples of typical low-Ti pyroxene $\left(0.18\right.$ and $0.03 \mathrm{wt} . \% \mathrm{TiO}_{2}$, respectively) as compared to a sample (DSM-AUG01) with relatively high $\left(0.83 \mathrm{wt} . \% \mathrm{TiO}_{2}\right)$ Ti content. The spectrum of the Ti-enriched pyroxene displays nearly $100 \%$ reduction in the spectral contrast of the CA2 and CA3 band minima relative to the continuum of the $1000-800 \mathrm{~cm}^{-1}$ reststrahlen band.

Hamilton [1998]. On the basis of the majority of available samples, Hamilton [1998, 2000] defined "critical absorptions" (CA) as features that are consistently present in pyroxene spectra and have a $\Delta \varepsilon$ (where $\varepsilon$ is emissivity) greater than $20 \%$ of the total spectral contrast (band depth); the shortest wavelength emissivity minimum that meets this constraint is designated CA1, the longest wavelength CA of $n$ features is CAn. Using this criterion, Hamilton [1998, 2000] identified five critical absorptions for calcic (quadrilateral) clinopyroxenes and determined their average wave number position. However, in the 1998 study, three augite samples (WAR-5858, NMNH-122302, and DSM-AUG01) were identified as having spectral characteristics that appeared unusual for their general composition (Figure 1). In addition to a general decrease in spectral contrast, Hamilton [1998] observed that in the three unusual augite spectra, the CA2 band $\left(\sim 956 \mathrm{~cm}^{-1} ; \sim 10.5 \mu \mathrm{m}\right)$, which is generally readily apparent in typical clinopyroxenes, is reduced to a barely discernable shoulder on the short wavelength side of the CA3 feature. The strength of the narrow minimum on the broad CA3 feature also is reduced, causing the reststrahlen feature in the $1000-800 \mathrm{~cm}^{-1}(10-$ $12.5 \mu \mathrm{m})$ region to have a more symmetric shape than is typical for calcic clinopyroxenes [Hamilton, 1998]. The positions of critical absorptions 3-5 are within the standard deviation of the average for all calcic clinopyroxenes (the unusual samples are not included in the average) and thus do not exhibit anomalous behavior. The position of CA1 in the unusual pyroxenes is located consistently at lower wave numbers (shorter wavelengths) than the average for calcic clinopyroxenes, outside the standard deviation in two out of three cases. Examination of the chemical data for these three samples showed that they exhibit higher total $\mathrm{TiO}_{2}$ $(0.79-1.03$ wt. $\%)$ than the average $(0.04$ wt.\%, standard deviation $=0.06$ ) for the remaining 20 calcic clinopyroxene samples analyzed in that particular study, raising the question of whether elevated $\mathrm{TiO}_{2}$ content could produce the observed spectral features. Table 1 shows the major element chemistries of these three samples and that of one of the representative low-Ti samples shown in Figure 1. Kuznetsova et al. [1980] examined infrared transmission spectra of Ti-bearing pyroxenes and determined that the coordination of the $\mathrm{Ti}^{4+}$ atom could be distinguished in spectral data and thus the (dis)equilibrium conditions at the time of their formation determined; however, their spectral analysis is not directly applicable to emission/reflection studies due to differences between emission/reflection and transmission measurements.

[6] Typical abundances of titanium in quadrilateral calcic clinopyroxene (hereafter referred to as augite) are generally less than $0.8 \mathrm{wt} \%$ [Deer et al., 1992]. Clinopyroxenes with elevated $\mathrm{Ti}$ contents (up to $\sim 9$ wt. $\% \mathrm{TiO}_{2}$ ) are generally accompanied by elevated $\mathrm{Al}$ contents as well (as part of a paired substitution); they commonly form in low-silica, alkaline magmas [Deer et al., 1972] and are present in lunar rocks and some meteorites. The three relatively high-Ti clinopyroxene samples have 2.93-5.77 wt. $\% \mathrm{Al}_{2} \mathrm{O}_{3}$ (Table 1) vs. an average of 0.76 wt. $\% \mathrm{Al}_{2} \mathrm{O}_{3}$ (standard deviation $=0.57$ ) for the remaining 20 samples [Hamilton, 1998]. Hamilton [1998] speculated that the Ti content in the samples indicated that they may have formed during alkalic basalt eruptions, with the unusual spectral character of the samples resulting from the relatively high $\mathrm{Ti}$ content and possible disorder in the pyroxene structure induced by rapid cooling.

[7] To confirm the hypothesis that elevated $\mathrm{Ti}$ abundance produces the unusual spectral character observed by Hamilton [1998], I sought a relatively pure sample contain- 
Table 1. Electron Microprobe Chemical Compositions ${ }^{\mathrm{a}}$

\begin{tabular}{|c|c|c|c|c|c|}
\hline & DSM-AUG01 & NMNH-122302 & WAR-5858 & AdoR Fassaite $^{\mathrm{b}}$ & NMNH-R15161 \\
\hline $\mathrm{SiO}_{2}$ & 50.27 & 47.97 & 50.58 & 45.90 & 54.06 \\
\hline $\mathrm{TiO}_{2}$ & 0.83 & 1.03 & 0.79 & 2.16 & 0.03 \\
\hline $\mathrm{Al}_{2} \mathrm{O}_{3}$ & 2.93 & 5.77 & 3.23 & 10.00 & 0.71 \\
\hline $\mathrm{Cr}_{2} \mathrm{O}_{3}$ & 0.03 & 0.00 & 0.00 & 0.21 & 0.00 \\
\hline $\mathrm{Fe}_{2} \mathrm{O}_{3}{ }^{\mathrm{c}}$ & 3.98 & 5.2 & 3.42 & n.d. & 1.31 \\
\hline $\mathrm{FeO}$ & 4.74 & 3.83 & 4.05 & 6.70 & 2.78 \\
\hline $\mathrm{MnO}$ & 0.26 & 0.27 & 0.16 & 0.06 & 0.17 \\
\hline $\mathrm{MgO}$ & 15.01 & 13.36 & 16.82 & 10.60 & 15.86 \\
\hline $\mathrm{CaO}$ & 21.26 & 21.33 & 19.81 & 24.10 & 24.75 \\
\hline $\mathrm{Na}_{2} \mathrm{O}$ & 0.41 & 0.66 & 0.36 & $<0.02$ & 0.37 \\
\hline $\mathrm{K}_{2} \mathrm{O}$ & 0.00 & 0.00 & 0.01 & n.d. & 0.00 \\
\hline Total & 99.72 & 99.41 & 99.21 & 100.01 & 100.04 \\
\hline
\end{tabular}

ing high-Ti pyroxene for spectral analysis and comparison to the spectra of the three unusual pyroxenes. I chose to use a sample of the Angra dos Reis meteorite for this purpose. Angra dos Reis (AdoR) is an achondritic meteorite that fell near Rio de Janeiro, Brazil in 1869, and was the first of a group of meteorites to be classified as "angrites". Angra dos Reis is composed of approximately 93 vol.\% fassaite (pyroxene), with $\sim 6$ vol.\% olivine, and assorted minor phases [Ludwig and Tschermak, 1887; Prinz et al., 1977], although one thin section may display up to 98 vol.\% fassaite [Treiman, 1989]. Deer et al. [1972] do not include $\mathrm{Ti}$ in their chemical definition of fassaite (calcic clinopyroxene with high $\mathrm{Ca}$, high but variable $\mathrm{Al}$, and high $\mathrm{Fe}^{3+}$ to $\mathrm{Fe}^{2+}$ ratio), and prefer the terms titaniferous or titanaugites for Ti-enriched calcic clinopyroxene. However, the term fassaite traditionally has been used in describing Angra dos Reis pyroxene [Prinz et al., 1977], which also includes a relatively high amount of Ti (Table 1). Fassaite in Angra dos Reis does not exhibit any petrographic evidence for strain, which potentially could affect the thermal infrared spectrum [e.g., Bunch et al., 1968]. Because its mineralogy is dominated by a Ti-enriched clinopyroxene, Angra dos Reis presents a viable sample for spectral analysis and comparison to the three unusual pyroxene spectra of Hamilton [1998]. The sample of Angra dos Reis used here (USNM111) was obtained on loan from the meteorite collection of the National Museum of Natural History at the Smithsonian Institution.

\section{Data}

[8] Four samples were used in this study. Three pure pyroxene samples [from Hamilton, 1998] are coarse particulate samples $710-1000 \mu \mathrm{m}$ in size. Spectra of samples of this size range are appropriate for the analysis of bedrock, rocky materials, and coarse particulates (down to $\sim 65 \mu \mathrm{m})$. The sample of Angra dos Reis is a small piece of rock, approximately $1 \mathrm{~cm}^{3}$ in size. An unweathered, cut surface of the meteorite was observed during the spectral analysis. Thermal infrared emission spectra (2000$\left.220 \mathrm{~cm}^{-1}, 5-45 \mu \mathrm{m}\right)$ of three samples were acquired on a Nicolet Nexus 670 spectrometer at the Thermal Emission Spectroscopy Laboratory at Arizona State University. The fourth spectrum (WAR-5858) was acquired previously on a Mattson Cygnus 100 spectrometer at ASU and covers the range $2000-400 \mathrm{~cm}^{-1}(5-25 \mu \mathrm{m})$; this sample is no longer available for analysis with the newer spectrometer, but all pyroxene features discussed here are included in this range. Each spectrum was acquired over a period of approximately five and a half minutes, with 270 scans averaged internally to produce the spectrum. The raw data were calibrated and converted to emissivity via the approach described by Ruff et al. [1997]. The emission spectra of all four samples are shown in Figure 2.

\section{Results and Discussion}

[9] Visual inspection of Figure 2 shows that to first order, the spectrum of Angra dos Reis provides a very good match to the Hamilton [1998] augite spectra, including the lack of a well-defined CA2 feature. The positions of the meteorite band minima correspond well with the features in the augite spectra, falling within the minimum and maximum wavelength positions observed for those samples (Table 2). The presence of olivine in the meteorite contributes at most $\sim 6 \%$ of the spectral signal, and is essentially unnoticeable by visual inspection. Test spectral mixtures of $6 \%$ olivine and 94\% Ti-pyroxene nonetheless indicate that minor shifts $\left(<10 \mathrm{~cm}^{-1}\right)$ in band minima toward lower wave number might be introduced due to the presence of olivine, so band positions reported here for Angra dos Reis represent the lowest possible wave number position. The band minima of the four samples do not show a statistically significant trend (with increasing wt.\% $\mathrm{TiO}_{2}$ ) of shifting to either longer or shorter wavelengths relative to the average clinopyroxene CA positions [Hamilton, 1998, 2000], and all positions but CA1 are near or within the standard deviation of the average for calcic clinopyroxenes. As stated above, the CA1 position in Ti-enriched samples is located consistently at lower wave numbers (shorter wavelengths) than the average for calcic clinopyroxenes, outside the standard deviation in three out of four cases (including the meteorite), but CA1 position is not distinctive enough to demonstrate a correlation with $\mathrm{Ti}$ content in the samples.

[10] The most distinctive spectral characteristic of the Ti-enriched samples is the lack of a well-defined CA2 band minimum. The similarity between the Angra dos Reis spectrum and the spectra of the three augites lends support to the hypothesis that substitution of $\mathrm{Ti}$ (and associated Al) into the clinopyroxene structure is the likely cause of the difference in spectral character relative to low-Ti quadrilateral calcic clinopyroxenes. Angra dos Reis 


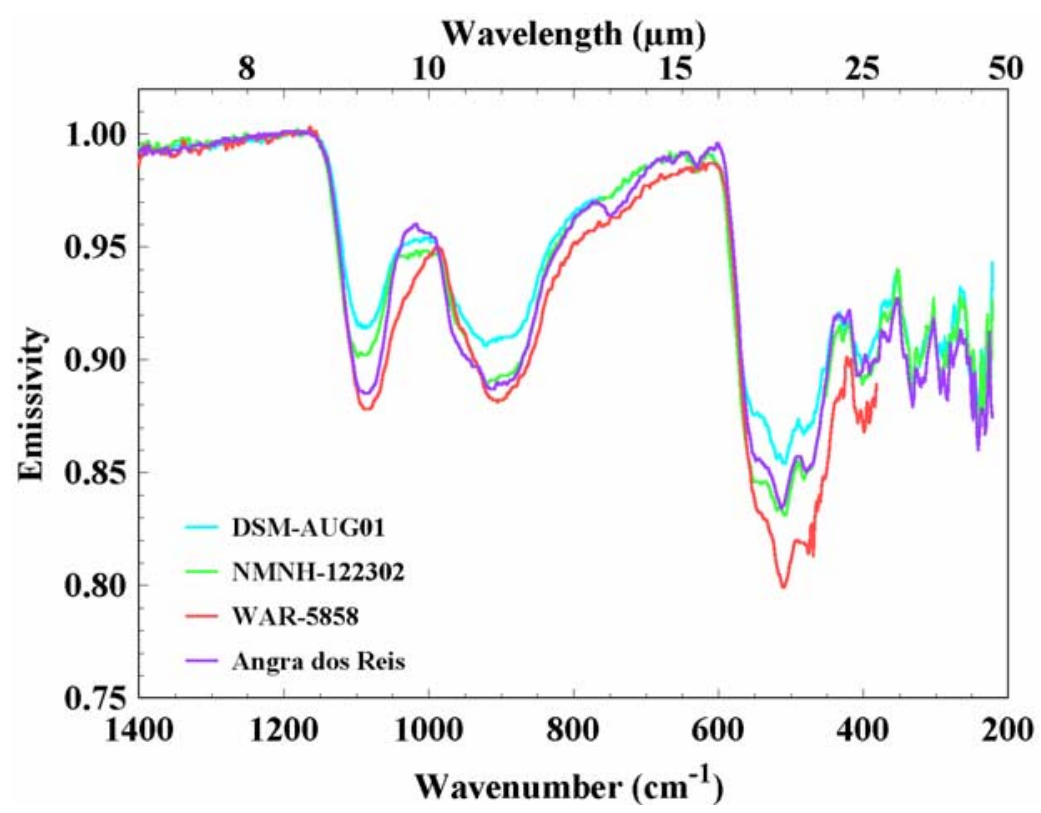

Figure 2. Thermal infrared emission spectra of three Ti-enriched calcic clinopyroxenes and the Angra dos Reis meteorite.

fassaite contains approximately $2.16 \mathrm{wt} . \% \mathrm{TiO}_{2}$, which is twice as much as the most Ti-rich sample of the Hamilton group. According to Deer et al. [1972], augites with $1-2$ wt. $\% \mathrm{TiO}_{2}$ are considered titaniferous, whereas titanaugites have $>2$ wt. $\% \mathrm{TiO}_{2}$; their 12 example analyses of titanaugites have $\sim 3-5.7$ wt. $\% \mathrm{TiO}_{2}$. Thus the samples studied here only cover a small range of possible natural $\mathrm{Ti}$ contents, and yet it appears that relatively small abundances of additional $\mathrm{Ti}$ (as little as $\sim 0.8 \mathrm{wt} \%$ in this study), accompanied by $\mathrm{Al}$, can have a strong effect on the thermal infrared spectrum. The highest $\mathrm{TiO}_{2}$ abundance in the 20 low-Ti samples is 0.20 wt.\% [Hamilton, 2000]; the threshold abundance for producing the observed spectral changes must therefore lie between $\sim 0.20-0.80$ wt. $\%$. Within the compositional range of the samples studied here, once the threshold abundance of $\mathrm{TiO}_{2}$ required to produce spectral changes is exceeded no other substantial changes in the spectrum are produced with increasing $\mathrm{TiO}_{2}$ content. Because the range of $\mathrm{Ti}$ abundances in natural samples is considerably larger than that covered by the samples in this study, further spectral changes with increasing Ti abundance cannot be ruled out and are worth investigating.

[11] Small amounts of cations other than Ti commonly substitute into the quadrilateral calcic clinopyroxene structure (e.g., $\mathrm{Na}^{+}, \mathrm{Mn}^{2+}$ in the M2 site), raising the question of whether such samples can be distinguished from samples where $\mathrm{Ti}$ is the substituting element. Hamilton [2000] showed that calcic clinopyroxenes with elevated $\mathrm{Na}$ contents also display some weakening of the CA2 feature relative to typical augites (although not to the degree observed with Ti-enriched pyroxenes), but they also exhibit a small emission minimum at $\sim 883 \mathrm{~cm}^{-1}(\sim 11.3 \mu \mathrm{m})$ that is not observed in calcic clinopyroxenes with M2 sites filled by $\mathrm{Ca}$ or in the Ti-enriched samples in this study. Some clinopyroxenes exhibit limited solid solution with a Mn-rich end-member (johannsenite) [Cameron and Papike, 1982; Deer et al., 1992] and also display spectral variations that differ from those exhibited by $\mathrm{Na}$ - and Ti-bearing, or typical samples (for details, see Figures 12 and 13 and discussion of Hamilton [2000]). Therefore thermal infrared spectral variations resulting from cation substitution are different for different elements.

[12] Hamilton [1998] hypothesized that higher $\mathrm{Ti}$ contents indicated the possibility of rapid cooling, which by inducing structural disorder, might be a cause of the anomalous spectral behavior of these pyroxenes. Ramsey [1996] showed that an alkali feldspar quenched above the 2-phase field exhibited a noticeable decrease in fine scale spectral features and the increasing dominance of a "silicate glass" shape. Although no studies have demonstrated the

Table 2. Critical Absorption Positions ${ }^{\mathrm{a}}$

\begin{tabular}{|c|c|c|c|c|c|c|}
\hline Critical Absorption & Average Hamilton $\mathrm{cpx}^{\mathrm{b}}$ & Standard Deviation & DSM-AUG01 & NMNH-122302 & WAR-5858 & Angra dos Reis \\
\hline CA1 & 1108 & 13 & 1084 & 1097 & 1084 & 1088 \\
\hline CA2 & 956 & 6 & sh & sh & sh & $\mathrm{sh}$ \\
\hline CA3 & 915 & 9 & 920 & 920 & 905 & 910 \\
\hline CA4 & 543 & 14 & $550 \mathrm{sh}$ & $548 \mathrm{sh}$ & $546 \mathrm{sh}$ & $548 \mathrm{sh}$ \\
\hline CA5 & 477 & 6 & 482 & 482 & 478 & 478 \\
\hline
\end{tabular}

a"sh" indicates feature is present only as a shoulder on another absorption.

${ }^{\mathrm{b}}$ Averages have been recalculated to exclude DSM-AUG01, NMNH-122302, and WAR-5858. 
progressive effects of quenching on pyroxenes, it is possible that such effects would be greater than the effects observed in these samples. Also, in hindsight, the mean particle size of the Hamilton pyroxene samples $(710-1000 \mu \mathrm{m})$ is large enough that the crystals from which the samples were derived would have been too large to be consistent with rapid cooling; this also suggests that disorder in the pyroxene structure is unlikely to be the cause of the unusual spectral character, and that increased $\mathrm{Ti}$ (and $\mathrm{Al}$ ) content is the likely culprit. Ultimately, the vibrational modes (and hence spectral shapes) change because each element that can substitute into a given cation site will have a slightly different bonding environment with the anions around it. Nearly end-member pyroxenes exhibit well-defined band shapes (e.g., NMNHR15161 in Figure 1) because substituting elements are not present to distort the mineral's structure and bonding, and thus the vibrational modes. Titanium can substitute into the $\mathrm{Y}$ (M1) site or into the $\mathrm{Z}$ (for $\mathrm{Si}$ ) site if there is insufficient $\mathrm{Al}$ to fill the $\mathrm{Z}$ site. Titanium and Al substitution are typically linked, and both substitutions contribute to changing the structural and bonding configurations that determine the vibrational spectrum. This study demonstrates that the configuration of the mineral structure is distorted by this substitution and the vibrational modes are modified, reducing the clarity of their appearance in the spectrum.

\section{Application to Unknown Spectra and Remote Sensing Data}

[13] Ultimately, it is desirable to apply our understanding of pyroxene spectral variations as a function of composition to the determination of pyroxene content in unknown samples, such as pure minerals, rocks or their derivative sands, etc., as is commonly practiced in laboratory and remote sensing applications. As described above, linear deconvolution modeling of the modal mineralogies of rock samples using their thermal infrared spectra has demonstrated that discrimination of solid solution composition $(\mathrm{Mg} /$ $[\mathrm{Mg}+\mathrm{Fe}]$ in pyroxenes, or $\mathrm{An} /[\mathrm{An}+\mathrm{Ab}]$ in plagioclase feldspars) can be achieved to within defined uncertainties when the appropriate end-members are available [Hamilton et al., 1997; Hamilton, 1998; Hamilton and Christensen, 2000; K. A. Milam et al., Accuracy of plagioclase compositions from laboratory and Mars spacecraft thermal emission spectra, submitted to Journal of Geophyiscal Research, 2003 (hereinafter referred to as Milam et al., submitted manuscript, 2003)]. Whether or not Ti-bearing pyroxene compositions can be distinguished in the relatively more complicated spectrum of a mixture (i.e., a rock) remains to be quantitatively tested. However, on the basis of the significant differences observable in the spectra of pure minerals demonstrated here, and prior modeling studies, it is not unreasonable to assume that in cases where Ti-enriched pyroxene is the dominant pyroxene composition, it should be detectable if a Ti-enriched pyroxene of similar quadrilateral chemistry is included as an option in the model.

[14] To provide an initial quantitative analysis of whether Ti-enriched pyroxenes can be identified in the spectrum of an "unknown", I performed a test using a linear deconvolution algorithm and a synthetic mixture spectrum containing a Ti-pyroxene component. Briefly, the linear deconvolution algorithm employs a user-provided set of mineral spectra (end-members) to "unmix" a mixture spectrum, identifying its mineral components and determining the abundance of each mineral present via a linear matrix inversion [Ramsey and Christensen, 1998]. This approach is viable because under certain well-known (and common) conditions, the spectrum of a rock or mixture is equivalent to the linear sum of the mineral spectra. A synthetic mixture is an idealized representation of a natural mixture, and provides a best case scenario; if the spectra used to make the synthetic mixture are included in the end-member set, a perfect result will be obtained. I did not include all of the synthetic mixture spectra in the end-member set, and so a perfect fit cannot be obtained; the end-members used and the effects on the model fit are described below.

[15] Lunar basalts are one example of rocks that are characterized by high titanium contents (both from sample analyses and visible/near infrared remote sensing), and have substantial abundances of Ti-enriched pyroxene. The Basaltic Volcanism Study Project [1981] published modal mineralogies of lunar basalts, which are used here to create a synthetic basalt spectrum that roughly represents that of an Apollo 12 sample. The synthetic spectrum was created from the linear sum of five laboratory spectra (Ti-enriched pyroxene, pigeonite, plagioclase feldspar, olivine, and ilmenite) in proportion to their modal abundance (Table 3). To test whether Ti-pyroxene is distinguishable in this mixture, I used a linear deconvolution algorithm to model the synthetic spectrum, providing a set of mineral spectra to the algorithm that includes 12 spectra from a compositional range of feldspars (3 total), olivines (3), pyroxenes (5, including a different Ti-px than used in the synthetic mixture), and ilmenite (1). For the test to be successful the model must identify the Ti-pyroxene as being present; if the test fails, the pyroxenes will be modeled by other pyroxene compositions. I have performed the deconvolution four times, twice at laboratory spectral resolution $\left(4 \mathrm{~cm}^{-1}\right)$ and twice at the lowest Mars Global Surveyor Thermal Emission Spectrometer resolution $\left(20 \mathrm{~cm}^{-1}\right)$. At a given resolution, the deconvolution is performed once (Model 1) using all of the end-members above and a second time (Model 2) using only end-members that were not used to make the synthetic spectrum (ilmenite and pigeonite are permitted, because no alternate spectra exist). The low-resolution tests are designed to address whether Ti-pyroxene can be distinguished from other pyroxenes at spectral resolutions comparable to those measured by remote sensing instruments.

[16] The results of the test deconvolutions demonstrate that at laboratory and realistic remote sensing spectral resolutions, the correct pyroxenes are identified in a model of the basaltic spectrum; in other words, Ti-pyroxene is successfully distinguished from a "normal" high-Ca quadrilateral pyroxene (Table 3). Figure 3 shows the synthetic mixture spectra compared to the Model 2-derived spectra; the modeled spectra compare extremely well to the mixture spectrum, indicating excellent fits, and the modal abundance percentages derived in the models are well within the uncertainties of the technique [e.g., Ramsey and Christensen, 1998; Wyatt et al., 2001]. The small absolute ( $3-5 \%)$ but large relative $(\sim 100 \%)$ changes in CA 2 and CA 3 band strength and shape in Ti-pyroxenes are distinguishable in mixture spectra and at resolutions comparable to many 
Table 3. Linear Deconvolution Abundances ${ }^{\mathrm{a}}$

\begin{tabular}{|c|c|c|c|c|c|}
\hline Phase & $\begin{array}{c}\text { Test } \\
\text { Mixture }\end{array}$ & $\begin{array}{c}\text { Model1@ } \\
\text { Lab Resol. }\end{array}$ & $\begin{array}{c}\text { Model } 2 @ \\
\text { Lab Resol. }\end{array}$ & $\begin{array}{l}\text { Model1@ } \\
\text { TES Resol. }\end{array}$ & $\begin{array}{l}\text { Model } 2 @ \\
\text { TES Resol. }\end{array}$ \\
\hline Plagioclase & 25 & 27 & 33 & 26 & 33 \\
\hline Pigeonite & 30 & 31 & 30 & 32 & 30 \\
\hline Ti-cpx & 30 & 23 & 23 & 23 & 24 \\
\hline Ca-cpx ${ }^{b}$ & 0 & 0 & 0 & 0 & 0 \\
\hline Olivine & 5 & 7 & 5 & 8 & 5 \\
\hline Ilmenite & 10 & 11 & 10 & 11 & 9 \\
\hline Total & 100 & 99 & 101 & 100 & 101 \\
\hline RMS error, \% & N/A & 0.108 & 0.121 & 0.101 & 0.134 \\
\hline
\end{tabular}

${ }^{\mathrm{a}}$ Model 1 permits all mixture spectra in end-member set (except Ti-px). Model 2 excludes all mixture spectra from end-member set (except ilmenite and pigeonite).

${ }^{\mathrm{b}} \mathrm{Ca}-\mathrm{cpx}$ refers to quadrilateral cpx, not enriched in Ti.

remote sensing instruments. The Ti-pyroxene is slightly underestimated, likely because most of the spectra used to make the mixture spectrum are not exactly the same spectra as in the end-member set provided to the algorithm. The degree of success achievable for such discriminations both in the lab and in remotely acquired data is likely to be dependent on the total abundance of the pyroxene present, with greater abundances yielding more accurate results, as well as spectral resolution, signal-to-noise ratio, and an appropriate set of end-member spectra.

[17] Obtaining more precise chemical information about $\mathrm{Ti}$ in pyroxene through its identification using thermal infrared spectroscopy may provide supporting information and/or greater confidence about the silica abundance and alkalinity of the parent magmas of lithologies measured in the laboratory and by remote sensing instruments. For example, the lab spectrum of a field sample that is modeled as having mineralogy consistent with relatively low-silica basalt (e.g., low plagioclase abundance, some alkali feldspar, etc.) might also be expected to have a calcic clinopyroxene best matched by a Ti-enriched pyroxene. Deconvolution models that include both high- and low Ti pyroxenes may indicate zonation in Ti-pyroxenes, in much the same way as has been demonstrated for feldspars (Milam et al., submitted manuscript, 2003). There are data sets from numerous past, present, and future planetary (Martian and terrestrial) remote sensing instruments with the requisite spectral resolution to distinguish these features, including: the Mars Global Surveyor Thermal Emission Spectrometer (TES), the Mars Exploration Rover MiniTES, the Mariner Mars Infrared Spectrometer (IRS), the Mariner Mars Interferometer Spectrometer (IRIS), the Advanced Hyperspectral Imager (AHI), and the Spatially Enhanced Broadband Array Spectrograph System (SEBASS). I argue that it is valuable to include a representative Ti-enriched pyroxene endmember in deconvolutions of thermal infrared spectra from any data set that is likely to contain pyroxenebearing lithologies and meets the basic spectral resolution requirements outlined here (signal-to-noise requirements are not defined here). Although thermal infrared spectra can be difficult to interpret for dusty and airless (or nearly so) bodies, the Moon (and possibly Mercury by analogy) is known to have significant abundances of $\mathrm{Ti}$ in ilmenite and pyroxene [Papike et al., 1991], and mapping of basaltic surfaces having variable abundances of Ti-enriched pyroxenes might provide additional information about mineralogical repositories for Ti. On Mars, TES has identified pyroxene [e.g., Bandfield et al., 2000; Christensen et al., 2000], and the Nakhla and Lafayette meteorites, accepted as Martian samples, contain augite with $0.11-0.43 \mathrm{wt}^{0} \% \mathrm{TiO}_{2}$ [Smith et al., 1983], which is within the threshold range determined here, suggesting that Ti-pyroxene could be present on Mars as a modally significant phase. Deconvolutions of a Nakhla spectrum (V. E. Hamilton, unpublished data) include a Ti-enriched pyroxene in the best-fit model. The Thermal Emission Spectrometer (TES) provides a global hyperspectral data set that has not been explored in depth yet, and deconvolution

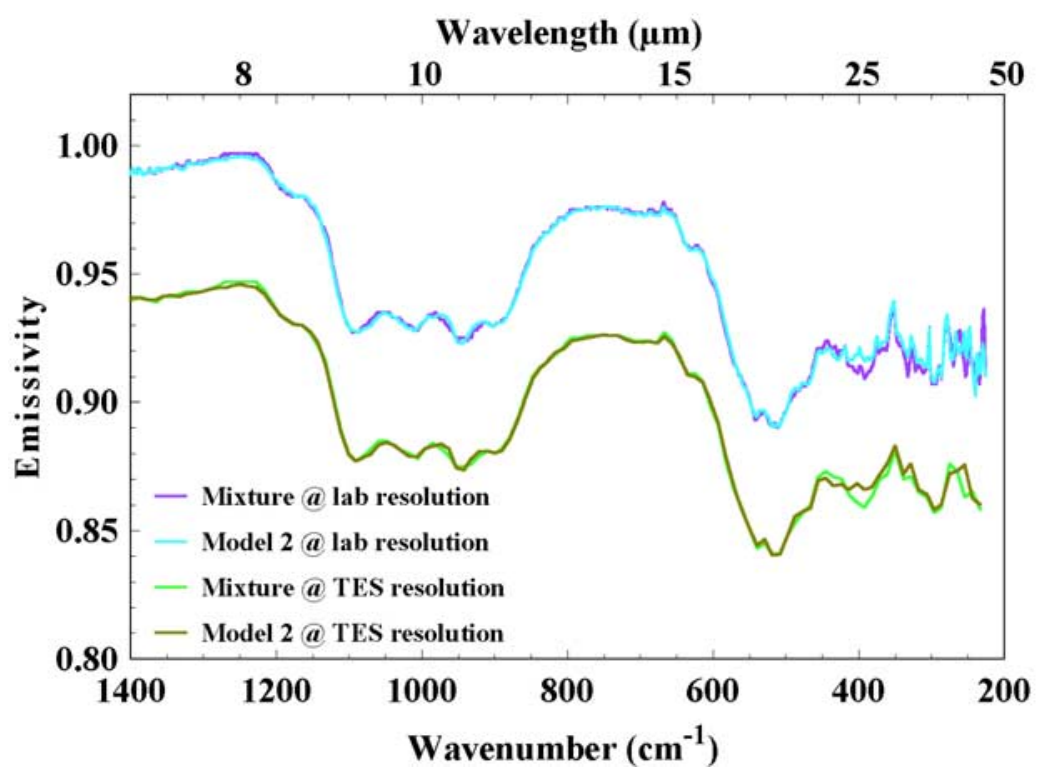

Figure 3. Synthetic mixture spectra and deconvolution (Model 2) spectra. Upper pair are shown at $4 \mathrm{~cm}^{-1}$ spectral resolution. Lower pair (offset 0.05 for clarity) are shown at $20 \mathrm{~cm}^{-1}$ resolution. 
models of data that include Ti-pyroxenes may discover regions of different basaltic composition than identified to date.

\section{Conclusions}

[18] 1. The thermal infrared spectra of relatively titaniumenriched calcic clinopyroxenes differ significantly from spectra of low titanium samples, and are well matched by the spectrum of Angra dos Reis, a meteorite dominated by titanium-rich pyroxene.

[19] 2. On the basis of the samples included in this study, relatively small amounts of $\mathrm{Ti}$ (and paired $\mathrm{Al}$ ) substitution can strongly affect the spectral character of calcic clinopyroxene spectra. The threshold abundance for producing the observed spectral changes appears to lie between $\sim 0.20$ 0.80 wt. $\% \mathrm{TiO}_{2}$. Within the range of wt. $\% \mathrm{TiO}_{2}$ covered by the samples in this study, relative abundances of $\mathrm{TiO}_{2}$ are not discriminated.

[20] 3. Augites exhibiting Ti substitution have thermal infrared spectral characteristics that distinguish them from low-Ti augites, as well as augites exhibiting $\mathrm{Na}$, or $\mathrm{Mn}$ substitution.

[21] 4. The results here are applicable to laboratory studies, but they also have relevance to and implications for remote sensing data analysis. Initial quantitative testing shows that Ti-enriched pyroxene is distinguishable in a rock-like mixture. This distinction is not significantly affected by a reduction in spectral resolution comparable to that of remote sensing instruments. Additional research is underway to quantitatively test the accuracy of deconvolution models in distinguishing Ti-enriched augites in natural rocks.

[22] Acknowledgments. I would like to thank Tim McCoy and Gretchen Benedix at the National Museum of Natural History (Smithsonian Institution) for suggesting Angra dos Reis as a comparison sample and for loaning this sample to me for spectral analysis. I would also like to thank Phil Christensen for providing access to the Thermal Emission Spectroscopy Laboratory at Arizona State University. The reviews of Jim Bell, Paul Lucey, Mike Wyatt, Mike Ramsey, and an anonymous reviewer are greatly appreciated. This is HIGP publication 1277 and SOEST publication 6147.

\section{References}

Bandfield, J. L., V. E. Hamilton, and P. R. Christensen, A global view of Martian surface compositions from MGS-TES, Science, 287(5458), 1626-1630, 2000.

Basaltic Volcanism Study Project, Basaltic Volcanism on the Terrestrial Planets, 1286 pp., Pergamon, New York, 1981.

Bunch, T. E., A. J. Cohen, and M. R. Dence, Shock-induced structural disorder in plagioclase and quartz, in Shock Metamorphism of Natural Materials, edited by B. M. French, and N. M. Short, Mono Book, Baltimore, Md., 1968.

Cameron, M., and J. Papike, The crystal chemistry of silicate pyroxenes, Rev. Mineral., 7, 5-115, 1982.

Christensen, P. R., J. L. Bandfield, M. D. Smith, V. E. Hamilton, and R. N. Clark, Identification of a basaltic component on the Martian surface from Thermal Emission Spectrometer data, J. Geophys. Res., 105(E4), 9609-9621, 2000.

Deer, W. A., R. A. Howie, and J. Zussman, Rock-Forming Minerals, vol. 2A, Single-Chain Silicates, 668 pp., Halsted, New York, 1972.

Deer, W. A., R. A. Howie, and J. Zussman, An Introduction to the RockForming Minerals, 528 pp., Addison-Wesley-Longman, Reading, Mass., 1992.
Estep, P. A., J. J. Kovach, and C. Karr Jr., Infrared vibrational spectroscopic studies of minerals from Apollo 11 and Apollo 12 lunar samples, Proc. Lunar Sci. Conf. 2nd, 2137-2151, 1971.

Estep, P. A., J. J. Kovach, P. Waldstein, and C. Karr Jr., Infrared and Raman spectroscopic studies of structural variations in minerals from Apollo 11, 12, 14, and 15 samples, Geochim. Cosmochim. Acta, 3, suppl., 30473067, 1972.

Hamilton, V. E., Thermal infrared emission spectroscopy of the pyroxene mineral series and pyroxene-bearing lithologies, Ph.D. dissertation thesis, Ariz. State Univ., Tempe, 1998.

Hamilton, V. E., Thermal infrared emission spectroscopy of the pyroxene mineral series, J. Geophys. Res., 105, 9701-9716, 2000.

Hamilton, V. E., and P. R. Christensen, Determining the modal mineralogy of mafic and ultramafic igneous rocks using thermal emission spectroscopy, J. Geophys. Res., 105, 9717-9733, 2000.

Hamilton, V. E., P. R. Christensen, and H. Y. McSween Jr., Determination of Martian meteorite lithologies and mineralogies using vibrational spectroscopy, J. Geophys. Res., 102(E11), 25,593-25,603, 1997.

Kuznetsova, L. G., Y. Y. Poroshin, and D. M. Orlov, Titanium in the structure of clinopyroxenes and its petrogenetic significance, Int. Geol. Rev., 22(9), 1061-1066, 1980.

Lazarev, A. N., and T. F. Tenisheva, The vibrational spectra of silicates, II, Infrared absorption spectra of silicates and germanates with chain anions, Opt. Spectrosc., 11, 37-40, 1961a.

Lazarev, A. N., and T. F. Tenisheva, The vibrational spectra of silicates, III, Infrared spectra of the pyroxenoids and other chain metasilicates, Opt. Spectrosc., 11, 316-317, $1961 \mathrm{~b}$.

Ludwig, E., and G. Tschermak, Der meteorit von Angra dos Reis, Mineral. Petrogr. Mitt., 8, 341, 1887.

Lyon, R. J. P., Evaluation of infrared spectroscopy for compositional analysis of lunar and planetary soils, Final Rep. Contract NASr 49(04), Stanford Res. Inst., Stanford, Calif., 1962.

Omori, K., Analysis of the infrared absorption spectrum of diopside, Am. Mineral., 56, 1607-1616, 1971.

Papike, J. J., L. A. Taylor, and S. Simon, Lunar Minerals, in Lunar Sourcebook: A User's Guide to the Moon, edited by G. H. Heiken, D. T. Vaniman, and B. M. French, pp. 121-181, Cambridge Univ. Press, New York, 1991.

Prinz, M., K. Keil, P. F. Hlava, J. L. Berkley, C. B. Gomes, and W. S. Curvello, Studies of Brazilian meteorites, III, Origin and history of the Angra dos Reis achondrite, Earth Planet. Sci. Lett., 35, 317-330, 1977.

Ramsey, M. S., Quantitative analysis of geological surfaces: A deconvolution algorithm for midinfrared remote sensing data, Ph.D. thesis, Arizona State Univ., Tempe, 1996.

Ramsey, M. S., and P. R. Christensen, Mineral abundance determination: Quantitative deconvolution of thermal emission spectra, J. Geophys. Res., 103, 577-596, 1998

Ruff, S. W., P. R. Christensen, P. W. Barbera, and D. L. Anderson, Quantitative thermal emission spectroscopy of minerals: A technique for measurement and calibration, J. Geophys. Res., 102, 14,899-14,913, 1997.

Rutstein, M. S., and W. B. White, Vibrational spectra of high-calcium pyroxenes and pyroxenoids, Am. Mineral., 56, 877-887, 1971.

Ryall, W. R., and I. M. Threadgold, Evidence for $\left[\left(\mathrm{SiO}_{3}\right)_{5}\right]_{\infty}$ type chains in inesite as shown by X-ray and infrared absorption studies, Am. Mineral., 51, 754-761, 1966.

Smith, J. V., I. M. Steele, and C. A. Leitch, Mineral chemistry of the shergottites, nakhlites, Chassigny, Brachina, pallasites and urelites, Proc. Lunar Planet. Sci. Conf. 14th, Part 1, J. Geophys. Res., 88, suppl., B229-B236, 1983

Treiman, A. H., An alternate hypothesis for the origin of Angra dos Reis: Porphyry, not cumulate, Proc. Lunar Planet. Sci. Conf. 19th, 443-450, 1989.

Wyatt, M. B., V. E. Hamilton, H. Y. McSween Jr., and P. R. Christensen, Analysis of terrestrial and Martian volcanic compositions using thermal emission spectroscopy, 1, Determination of mineralogy, chemistry, and classification strategies, J. Geophys. Res., 106(E7), 14,711-14,732, 2001.

V. E. Hamilton, Hawai'i Institute of Geophysics and Planetology, University of Hawai'i, 2525 Correa Road, Honolulu, HI 96822, USA. (hamilton@higp.hawaii.edu) 